\title{
Social Influences and Smoking Behaviors Among Four Asian American Subgroups
}

\author{
Grace X. Ma ${ }^{1}$, Steve E. Shive ${ }^{2}$, Jamil Toubbeh ${ }^{1}$, Yin Tan ${ }^{1}$, Shanyang Zhao ${ }^{1}$ \\ ${ }^{1}$ Temple University \\ ${ }^{2}$ East Stroudsburg University
}

\begin{abstract}
This study sought to identify the predictive power of social influences on smoking behavior among Asian American adults. A cross-sectional self-report survey method and stratified-cluster proportional sampling technique was used. The survey was conducted at the 26 randomly selected Asian American community organization locations in the Delaware Valley region. A sample of 1374 was recruited from 26 selected organizations and 1174 completed the survey with an average response rate of $83 \%$. Social influences were measured by examining the predictive power of parental, other important family members' and friends' tobacco use prevalence on smoking behavior, and the perception of the number of people who smoke in the U.S. A Chi-Square test and logistic regression models were used to analyze the data. Current smoking father/brother, number of smoking friends, and gender were positively associated with current tobacco use. Asians who had an ever and current smoking father/brother and those who had current smoking friends were more likely to be current smokers. The youngest age group were more likely to be influenced by an ever and current smoking father/brother, by having close friends who smoke, and perceived the highest amount of peer pressure. The smoking rate was highest among the 22-45 age group. Successful smoking prevention and cessation programs designed for Asian Americans must take into consideration male parental tobacco use because it represents the primary source of learned behavior and this influence continues beyond adolescence.
\end{abstract}

(C) 2003 Californian Journal of Health Promotion. All rights reserved.

Keywords: social influences, tobacco, Asian American, smoking

\section{Introduction}

Social cognitive theory suggests that people can learn a new behavior by observing the behavior of others and the rewards associated with the observed behavior (Bandura, 1986). More often than not, behavior is learned from parents, other important family members, and friends. The smoking behaviors and attitudes of these significant others toward tobacco are important predictors of tobacco use among adults and children who share the same physical environment. Various studies have shown, for example, that parental tobacco use patterns have a significant impact on adolescent smoking behavior (Bauman, Foshee, Linzer, \& Koch, 1990; Friedman, Lichtenstein, \& Biglan, 1985; Moreno, Laniado-Laborin, \& Sallis, 1994;
Nolte, Smith, \& O'Rourke, 1983; Newman \& Ward, 1989). Nolte et al. (1983) and Newman \& Ward, (1989) found that parental smoking behaviors were more significant in adolescents' use of tobacco than other family members' smoking behavior or friends. These findings corroborated studies on Latino youth.

Latino youth whose parents smoked were more likely to smoke than those with nonsmoking parents (Moreno et al., 1994), Dusenbury, Kerner, Baker, Botvin, James-Ortiz, \& Zanber, 1992; \& Hu, Flay, Hedeker, Siddiqui, \& Day. Hu's study, however, revealed some deviation in these behavior patterns among the four ethnic groups he studied. While White, Hispanic and Other/Asian youth smoking behavior was 
heavily influenced by parents' smoking behavior, African American youth were the least affected by parental smoking patterns. This finding is similar to that of other researchers suggesting that, at least for African Americans, the assumption that parental smoking patterns are good predictors of youth smoking behavior does not hold (Castro, Maddahian, Newcomb, \& Bentler, 1987; Newcomb \& Bentler, 1986; Vega, Zimmerman, Warheit, Apospori, \& Gil, 1993; Landrine, Richardson, Klonoff, \& Flay, 1994).

There is a dearth of information on the relationship between parental smoking behavior and smoking behavior among Asian American youth. Although mentioned in a few studies for ethnic group comparative purposes, there are no studies focusing exclusively on the effects of parental and others' smoking on Asian American youth smoking behaviors ( $\mathrm{Hu}$, et al., 1995; Castro et al., 1987; Sussman, Dent, Flay, Hansen, \& Johnson, 1987). Hu et al. (1995) study showed that among White, African Americans, Hispanics, and Asians the impact of parental smoking on younger members of families was the strongest for Asians. While these results may imply that Asian American youth are more susceptible to cultural and parental influences than other ethnic youth, Hu's study did not differentiate between the 'Others' and the Asians in his mixed group. Studies on Vietnamese youth in Massachusetts indicated that parental smoking increased the risk of smoking among youth (Wiecha, 1996; Wiecha, Lee, \& Hodgkins,. 1998).

Several studies noted that peer use of tobacco represents the most important predictor of smoking behavior among White youth (Landrine, Richardson, Klonoff, \& Flay, 1994; Headen, Bauman, Deane, \& Koch, 1991). A study conducted by Botvin Epstein, Schinke, \& Diaz, 1994 of New York City minority youth, concluded that smoking prevalence among friends and peers was directly related to social influences such as family and friends. Landrine et al. (1994) concluded that the extent to which peer influences predicted smoking behavior varied significantly by ethnic background. In their study, they noted that among Whites, peer influence was the strongest predictor, followed by Latinos, Asians, and African Americans. Landrine's findings with regard to the strength of peer influence among African American youth is corroborated by other studies ( $\mathrm{Hu}$ et al., 1995; Newcomb et al., 1986; Vega et al., 1993; Sussman et al., 1987; Headen, 1991; Farrell,\& Danish, 1993). Hu et al. (1995) noted, however, that among all ethnic groups studied, friends' smoking behavior had the greatest impact on smoking behavior of youth. That impact superseded that of parents.

Other study findings on peer and friends' effect on youth smoking behavior showed inconsistent results. Among those that corroborated the above findings is the study by Dusenbury et al. (1992) of New York City Latinos, discussed above, the study conducted by Morris, Vo, Bassin, Savagio, \& Wong, (1993) study of Hispanic children showed that having smoking friends was an independent predictor of previous and past 30 day tobacco use; and Smith, McGraw, \& Carrillo's (1991) study of Puerto Rican American high school students revealed similar trends. In their study of school achievement and smoking behavior among California Hispanic students, Sussman et al. (1987) noted that peer smoking was a slightly better predictor of smoking than school achievement. Castro et al. (1987) study of Mexican-Americans, however, revealed that peer influence did not represent a strong factor in smoking behavior. Landrine et al. (1994) noted that the predictive power of peers depended largely on level of acculturation.

The influence of the smoking behavior of parents, other family members, peers and friends on the smoking behavior of Asian American youth remains the least explored. Although a number of researchers have included them in studies, the inclusion of other ethnic groups with these populations failed to either establish a pattern of, or to provide insight into the association between parents', other family members', peers' and friends' smoking behavior and Asian American youth smoking behavior (Hu et al., 1995; Castro et al., (1987; Sussman, et al., 1987; Wiecha, 1996; Wiecha et al., 1998). Moore, Elder, Young, Wildey, \& Molgaard, 
(1989) comparing the influence of important family members on the smoking behavior of youth, found that the influence was greatest among Asians and weakest among White youths. A study on a mixed population sample by Unger \& Chen (1999) suggested that siblings smoking increased the odds of smoking. Dusenbury et al. (1992) found that the number of siblings who smoked predicted experimental smoking and current smoking among Latino youth in New York City. The results of these studies warrant further study.

Notwithstanding a plethora of literature on the effects of parental, other important family members', peers' and friends' tobacco use on other individuals' smoking behavior, studies of social influences on Asian Americans' smoking behavior have been extremely rare. Two groups of researchers have noted that while Asian Americans may be more susceptible to parental influences, primarily because of filial duty and respect in Asian cultures, peers and friends may exert less social pressure on non-smokers, whether youth or adults ( $\mathrm{Hu}$ et al., 1995; Landrine, et al., 1994).

The overall smoking rate in the general U.S. population is $23.5 \%$ (CDC, 1992). Smoking prevalence estimates vary by ethnic/racial group: Whites (24.3\%), Blacks (24.3\%), Hispanics $(12.3 \%)$, and Alaskan Native $(40.8 \%)$ and Asian/Pacific Islander (15.1\%). Research on tobacco use prevalence using large populations has often masked the heterogeneity within specific racial/ethnic subgroups. The category of "Asian" is applied to a number of ethnic subgroups that can vary socially and culturally which effect certain behaviors such as smoking. In addition, immigration status is often overlooked as an influential factor in smoking status (Baluja, Park, \& Myers, 2003). For example, more than half $(61.4 \%)$ of the Asian American population is comprised of new immigrants (U.S. Census Bureau, 2000). Many of these immigrants settle proximal to or within neighborhoods with fellow Asians, often referred to as China town in metropolitan areas. Local studies of smoking patterns have shown smoking prevalence rates among immigrants that exceed those of U.S. born members (CDC,
1989). A study comprised mainly of Asian American immigrants showed that the overall Asian American smoking prevalence rate and Asian subgroup rates exceeded the rates of the U.S. general population (Ma, Shive, Tan, \& Toubbeh, 2002). The admixture of new and old immigrants, first and later generations, the effect of acculturation on behavior, and the dearth of information on risk and protective factors in Asian cultures make the design of appropriate smoking prevention and intervention programs for these communities a complex task.

Adult Asian Americans play important cultural roles in Asian communities and while their social influence is greatest among younger Asian Americans, they play other roles within families and the community where they not only influence others, but are also influenced by others. This interaction among adults is carried out in an environment where cigarettes and smoking are considered culturally acceptable.

This study examines the role of social influences on smoking status and presents three models of estimates for the predictive power that these social influences have on smoking behavior among Asian Americans in general, and by gender.

\section{Methods}

A cross-sectional, stratified-cluster proportional sampling technique was used. A detailed description of the design and validation process has been explained in another source (Ma et al., 2002). The dependent variables used in the study were respondent smoking status (nonsmokers, current smokers), father/brother or friends smoke, and perception of peers who smoke. Smoking status was determined for nonsmokers if they had never smoked, and current smokers if they smoked within the last 12 months. The independent variables included smoking status of family members and friends, ethnic subgroup (Chinese, Koreans, Vietnamese, and Cambodians), gender, and age.

\section{Sample}

The sample consisted of 1174 Asian Americans: 410 Chinese, 436 Korean, 196 Vietnamese, 100 Cambodian and 32 other-group participants (i.e. 
Thai, Laotians, and Asian Indians). The othergroup was excluded from this study. Distribution by gender and age were as follows: $55 \%$ were males and $44 \%$ females, ranging in age from 14 to 80 years $(M=41, S D=16)$. The current tobacco use rates among the four subgroups were: Chinese 24.1\%; Korean, 26.8\%; Vietnamese, $40.3 \%$; and Cambodian, $42.4 \%$. The educational level of participants ranged from less than high school to graduate level training. Characteristics and selection of the overall sample were reported elsewhere (Ma et al., 2002). All participants were 1) of Asian descent, 2) affiliated with the selected community organizations, 3) 18 years of age or older, and 4) voluntary participants in the survey.

The seven counties of PA and NJ selected for the survey are populated by a diverse mix of Asian Americans who represent various socioeconomic statuses, educational levels, and types of employment. The largest subgroups, representing $87 \%$ of Asian Americans in the seven counties in the Delaware Valley, include Chinese, Koreans, Vietnamese, and Cambodians (U.S. Bureau of Census, 1990).

\section{Measures}

A comprehensive smoking behavior questionnaire of 77-items was developed and comprised of ten sections related to smoking behavior. One section measured social influences. Social influence on smoking behavior was measured by six items on the questionnaire. Two items measured family influence by asking respondents whether family members ever smoked and currently smoke. Ten family members were provided for respondents to check. Peer influence was measured by three items which included a question if friends smoked (yes, no, I don't know), the percentage of peers who smoke (0$20 \%$ to $81-100 \%$ ), and how many friends smoke. The peer percentage variable was dichotomized into a majority ( $60 \%$ or more) of peers smoked and less than $60 \%$. The sixth item asked for an estimate of the percentage of Asians who smoke.

Since the respondents checked all that applied, each family member checked was coded as a "yes" response, and each family member that was left blank as a "no" response. An Exsmoker Family variable was created for each of the family members and was determined for those whom the response to family ever smoked was "yes" and Family Current was "no".

\section{Analysis}

SPSS 10.0 was used to analyze the data. Five separate Chi-Square tests of significance were used and included 1) analysis of the influence of family members' smoking behavior (current smokers and exsmokers) on respondent smoking behavior (nonsmokers, current smokers), 2) influence of race on the smoking status of father/brother and friends smoking, 3) differences in age and father/brother and friends smoking status, 4) differences in respondent smoking status and age, and 5) influence of age on the perception of peer smoking. Three logistic regression models were developed to analyze the influence of family members' smoking behavior and the number of friends who smoke on the respondent's smoking status, while controlling for ethnic group, gender, and age. For this analysis, age was dichotomized into over 21 years of age and under 21 years of age. This dichotomization was based on the National Institutes of Health's inclusion criteria for children (range: birth through 21 years) (U.S. DHHS, 2002) and the observation that Asian youth tend to acquire smoking behavior during the latter part of their teen years (Ma et al., 2002).

\section{Results}

\section{Behavior \\ Family Influences on Smoking}

Table 1 shows the results of $\chi^{2}$ tests for respondent smoking status and having family members who were ever smokers and current smokers. Current smokers were significantly more likely to have fathers and brothers who were current smokers than were nonsmokers. There were no significant differences between nonsmoking and current smoking respondents and having family members who were exsmokers. Current smoking respondents were also likely to have other members of the family who were current smokers, than nonsmoking 
respondents, however these differences were not significant.

There were significant differences between ethnic subgroups among current smokers who had a father/brother who ever and currently smoked but no significant differences were found between the groups if smokers had close friends who smoked (Figure 1). Korean (76.9\%) smokers were more likely to report having a father/brother who ever smoked than Cambodian $(72.1 \%)$, Chinese $(65.7 \%)$ and Vietnamese (45.6\%). Cambodians (53.5\%) were more likely to have a current smoking father/brother than Koreans (38.5\%), Chinese (38.4\%), and Vietnamese $(27.8 \%)$.

Table 1

Respondent Smoking Status by Family Member Smoking Status

\begin{tabular}{|l|c|c|c|c|c|}
\hline \multicolumn{1}{|c|}{$\begin{array}{c}\text { Ex-Smoking Family } \\
\text { Members }\end{array}$} & NonSmokers \% & $\begin{array}{c}\text { Current Smokers } \\
\text { \% }\end{array}$ & Chi-Squared & p & n \\
\hline Father & 36.7 & 35.2 & 0.23 & n.s. & 1013 \\
\hline Mother & 8.0 & 8.9 & 0.23 & n.s. & 1013 \\
\hline Brother & 11.7 & 10.1 & 0.62 & n.s. & 1013 \\
\hline Sister & 1.6 & 2.1 & 0.25 & n.s. & 1013 \\
\hline Grandfather & 10.2 & 12.4 & 1.12 & n.s. & 1013 \\
\hline Grandmother & 6.5 & 6.2 & 0.04 & n.s. & 1013 \\
\hline Husband & 15.5 & 11.0 & 1.02 & n.s. & 492 \\
\hline Wife & 0.8 & 2.3 & 1.86 & n.s. & 517 \\
\hline & & & & & \\
\hline Currently Smoking & & & & & \\
\hline Family Members & & & & & \\
\hline & 13.4 & 22.8 & 14.32 & $* * *$ & 1016 \\
\hline Father & 2.7 & 3.3 & 0.29 & n.s. & 1016 \\
\hline Mother & 14.3 & 26.3 & 21.81 & $* * *$ & 1016 \\
\hline Brother & 1.5 & 3.3 & 3.53 & n.s. & 1016 \\
\hline Sister & 1.8 & 3.6 & 3.10 & n.s. & 1016 \\
\hline Grandfather & 1.5 & 0.9 & 0.62 & n.s. & 1016 \\
\hline Grandmother & 19.7 & 19.2 & 0.01 & n.s. & 494 \\
\hline Husband & 0.8 & 1.5 & 0.60 & n.s. & 518 \\
\hline Wife & & & & \\
\hline Not & & & & & \\
\hline
\end{tabular}

Note: n.s. $=$ not significant

$* * * \mathrm{p}<.001$

Figure 2 shows that significant differences were found between age groups in having an ever smoking father/brother, $\left(\chi^{2}(3)=2.6, p<.001\right)$ and in having a current smoking friend, $\chi^{2}(3)=$ $15.3, \mathrm{p}<.05)$. The $\leq 21$ age group $(73.9 \%)$ was more likely to report having had a father/brother who ever smoked than the 22-45 (67.6\%), 46-65 $(61.4 \%)$, and $>66(60.0 \%)$ age groups. The youngest age group, $\leq 21$ age group was also the most likely to report having current smoking friends, than the 22-45 (66.9\%), 46-65 (67.1\%), and $>66(47.1 \%)$ age groups. 

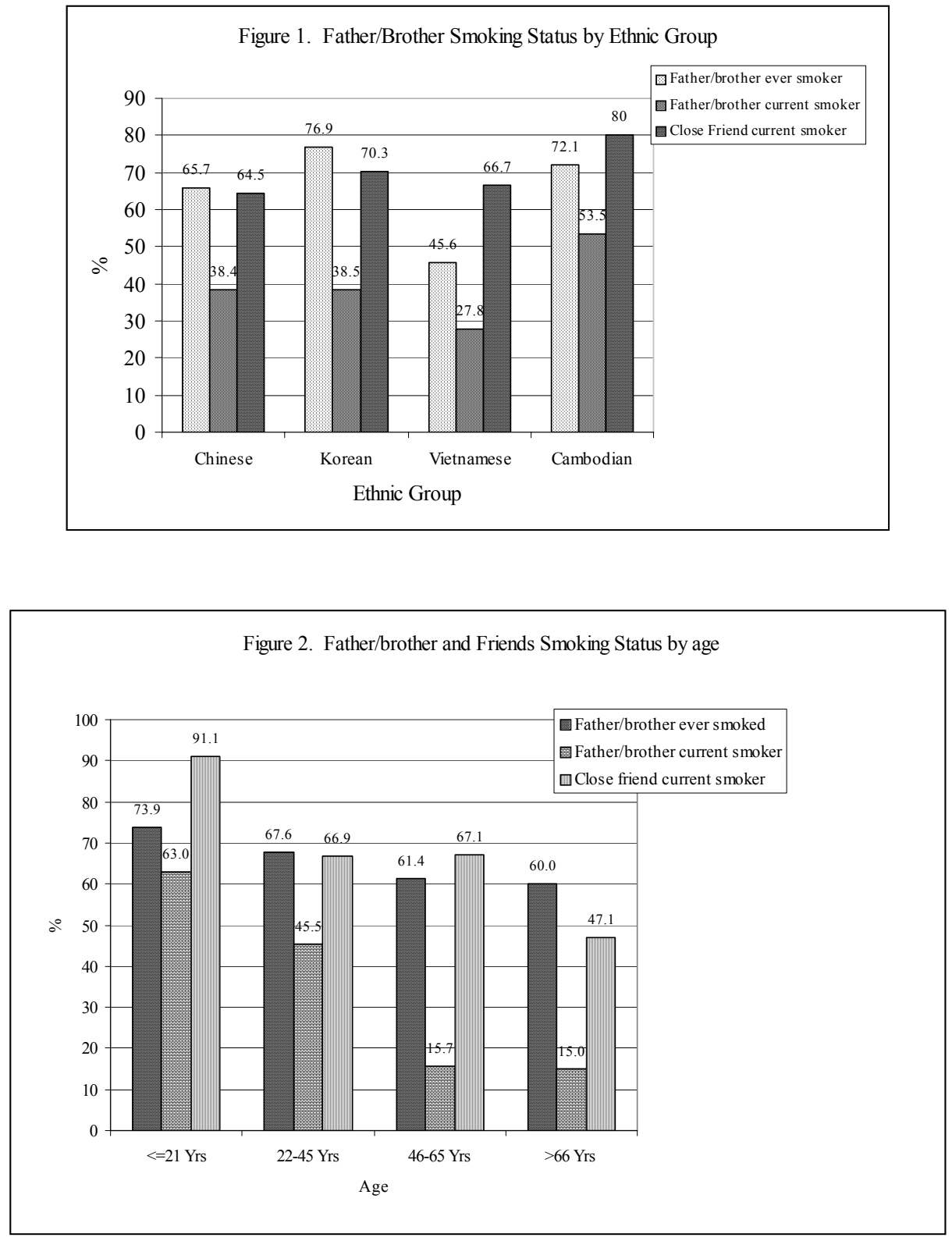

\section{Peer Influence on Smoking Behavior}

There was a significant difference between the age groups in current smoking rates, $\chi^{2}(3)=$ 13.7, $\mathrm{p}<.01$ ), as shown in Figure 3 . The highest reported smoking rate was among the $22-45$ age group $(34.9 \%)$, followed by the $\leq 21$ (28\%), 46-65 (24\%), and the $\geq 66(23.5 \%)$ age groups.
There was a significant difference in perception of the number of peers who smoke their age, with the youngest group, $\leq 21$ age group $(53.5 \%)$, having the highest perception of peer smoking among all age groups, $\chi^{2}(3)=102.4, p$ $<.001$ (Figure 4). 

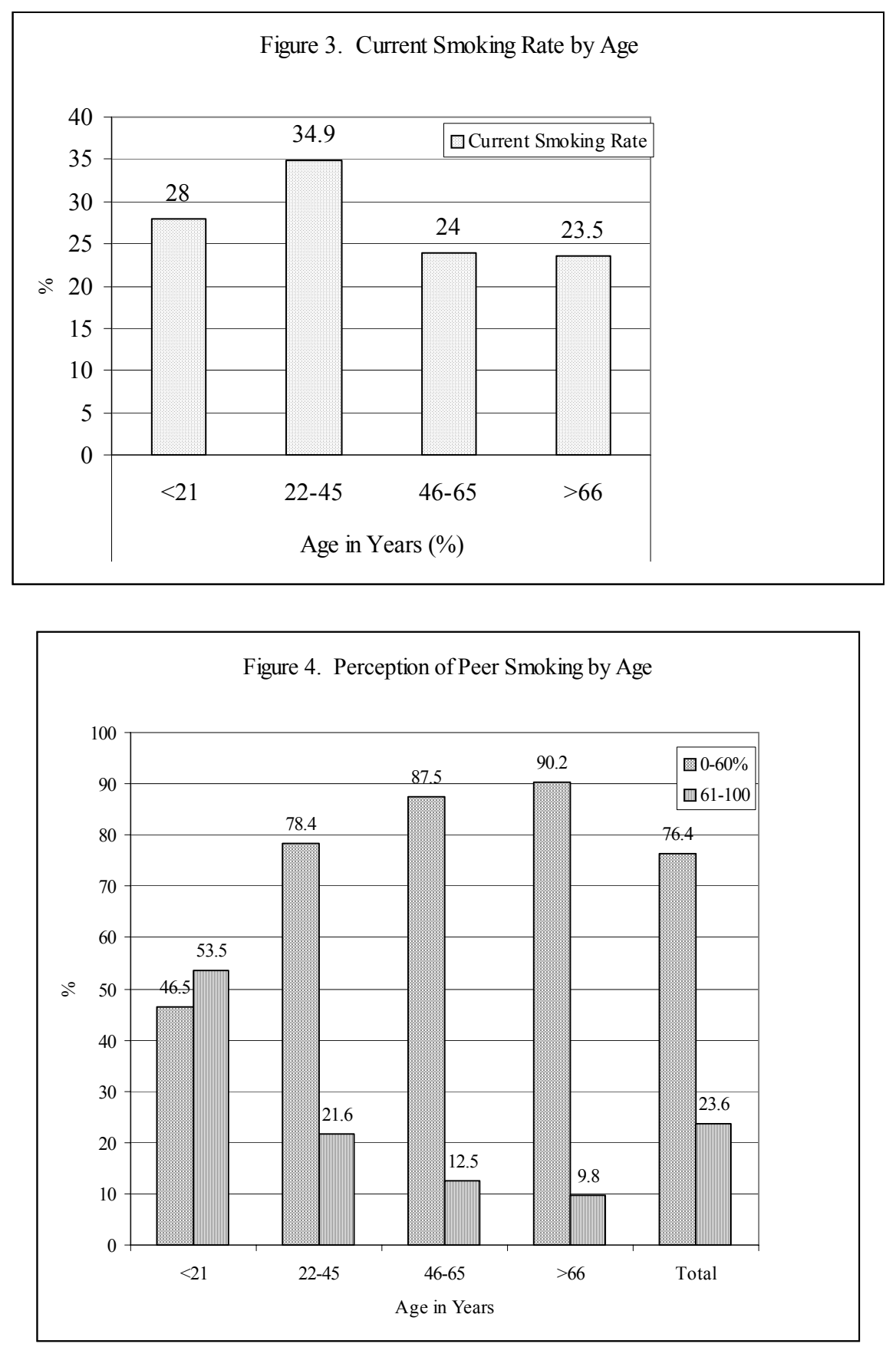

\section{Social Influences Associated with Current Smoking Status}

Table 2 shows the results of three logistic regression models. In the first model, current smoking fathers/brothers are not significant. The number of friends who smoke has a positive relationship with smoking. The more friends who smoke, the more likely the respondent is to be a current smoker. Chinese served as the reference group for the ethnic subgroup variable. Cambodian respondents were more than three times as likely $(\mathrm{OR}=3.6, \mathrm{p}<.001)$, Koreans were more than twice as likely $(\mathrm{OR}=2.2$, $\mathrm{p}<.01$ ), and Vietnamese respondents were almost twice as likely $(\mathrm{OR}=1.8, \mathrm{p}<.05)$ as Chinese respondents to smoke. Gender showed the greatest influence. Men were more than four times as likely as women to smoke $(\mathrm{p}<.001)$. 
Respondents over 21 years of age were more than twice as likely to smoke as younger respondents $(\mathrm{p}<.001)$.

Due to the very large influence of gender $(\mathrm{OR}=$ 4.1) on smoking, an examination of the possibility of an interaction between the gender of the respondent and social influence was conducted. To accomplish this, two additional models were created, one for male respondents and one for females. In each model, we examined all of the independent variables from Model 1, excluding gender. Model 2 shows that having a father who smokes is a significant influence on smoking for men. Men whose father currently smokes were almost twice as likely to smoke than men whose father does not smoke $(\mathrm{OR}=1.9, \mathrm{p}<.05)$. However, having a brother who currently smokes is not a significant influence on smoking for men. Having more friends who smoke, being Cambodian or Korean, and being over 21 years of age all increase the likelihood of smoking for men. Note that although the odds ratio for Vietnamese $(\mathrm{OR}=1.7)$ is quite large, this variable is not significant for men. This failure to achieve significance may be due to the decrease in sample size from Model 1 to Model 2.

Model 3 shows the results for women. Interestingly, the only significant $(\mathrm{p}<.01)$ result is for the number of friends who smoke. The Odds Ratio of 1.2 indicates that as the number of friends who smoke increases, the likelihood of a woman to smoke increases. Note that as with the men, there is a marginally significant effect of being Vietnamese $(p<.10)$. When women and men are taken as a whole group, being Vietnamese (compared to the reference group of Chinese respondents) has a statistically significant effect on smoking. Thus, the mere marginal effects $(p<.10)$ for both men and women when examined separately do indeed appear to be a function of sample size. Thus it appears accurate to conclude that for both men and women, Vietnamese respondents are more likely than Chinese respondents to smoke, when controlling for all other factors in the model.
The differing results of Model 1 and Model 2 indicate that there is an interaction between gender and social influence on smoking. In other words, social influence has a stronger influence on men than on women. For women, only two variables increased the likelihood of smoking: having more friends who smoke and being Vietnamese. Men were influenced not only by these two variables: they were more likely to smoke if their father smokes, if they were Cambodian or Korean, and if they were over 21 years of age.

Furthermore, the relationship between peer percentage and smoking status was examined. The perception of peer smoking among current smokers was significantly higher than that of non-smokers, $\left(\chi^{2}(3)=4.01, \mathrm{p}<.05\right)$.

\section{Discussion}

Results of this study indicate that among Asian Americans, current smokers are more likely to have family members who were ever smokers and current smokers, especially fathers who is also a current smoker. This finding is consistent with previous studies that indicated that parental smoking increased the risk of smoking among their children $(\mathrm{Hu}, 1995$, Wiecha, 1996, Wiecha et al., 1998). These studies, however, did not reveal the differential impact of smoking parents on males and females in the family. This study revealed that smoking parents had a variable social influence on the smoking behavior of current male and female smokers. A current smoking father and peer smoking friends have significant influence on male smoking behaviors, while only peer smoking friends have significant influence on female smoking behaviors. Further, there were differences between the ethnic groups in having fathers/brothers who smoked, but there were no differences between the groups in having friends who smoked. The current study also showed that having a father/brother who smoked was more influential in the younger ages, when they are also more likely to have friends who smoke. 
Table 2

Final Logistic Regression for Smoking Respondents, Men, and Women

\begin{tabular}{|c|c|c|c|c|c|c|}
\hline & \multicolumn{2}{|c|}{$\begin{array}{c}\text { Model One } \\
\text { All Respondents } \\
(\mathrm{n}=599)\end{array}$} & \multicolumn{2}{|c|}{$\begin{array}{c}\text { Model Two } \\
\text { Men } \\
(n=364)\end{array}$} & \multicolumn{2}{|c|}{$\begin{array}{c}\text { Model Three } \\
\text { Women } \\
(n=234)\end{array}$} \\
\hline & $\begin{array}{l}\text { Odds } \\
\text { Ratio }\end{array}$ & $\mathrm{p}$ & $\begin{array}{l}\text { Odds } \\
\text { Ratio }\end{array}$ & $\mathrm{p}$ & $\begin{array}{l}\text { Odds } \\
\text { Ratio }\end{array}$ & $\mathrm{p}$ \\
\hline $\begin{array}{l}\text { Father Currently Smokes: Yes } \\
(\mathrm{No})^{\mathrm{a}}\end{array}$ & 1.53 & n.s. & 1.926 & * & 0.75 & n.s. \\
\hline $\begin{array}{l}\text { Brother Currently Smokes: Yes } \\
(\mathrm{No})^{\mathrm{a}}\end{array}$ & 1.31 & n.s. & 1.281 & n.s. & 1.69 & n.s. \\
\hline Number of Friends Who Smoke & 1.19 & $* * *$ & 1.188 & $* * *$ & 1.21 & $* *$ \\
\hline Cambodian (Chinese) ${ }^{\mathrm{b}}$ & 3.56 & $* * *$ & 4.179 & $* *$ & 2.35 & n.s. \\
\hline Korean $\left(\right.$ Chinese) ${ }^{\mathrm{b}}$ & 2.17 & $* *$ & 2.304 & $* *$ & 1.99 & n.s. \\
\hline${\text { Vietnamese }(\text { Chinese })^{b}}^{b}$ & 1.85 & $*$ & 1.723 & n.s. & 2.36 & n.s. \\
\hline Male (Female) & 4.06 & $* * *$ & $\mathrm{~N} / \mathrm{A}$ & --- & $\mathrm{N} / \mathrm{A}$ & --- \\
\hline 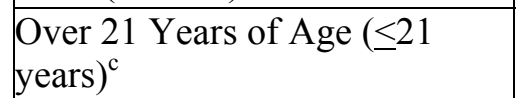 & 2.53 & $* *$ & 2.703 & ** & 1.91 & n.s. \\
\hline Constant & 0.01 & $* * *$ & 0.015 & $* * *$ & 0.02 & $* *$ \\
\hline
\end{tabular}

Note: n.s. = not significant

${ }^{\mathrm{a}}$ No is the reference group

${ }^{\mathrm{b}} \mathrm{Chinese}$ is the reference group

${ }^{c} \leq 21$ is the reference group

* $\mathrm{p}<.05$; ** $\mathrm{p}<.01 ; * * * \mathrm{p}<.001$

Cigarette smoking is considered both as an accepted social activity and a part of social interaction, especially among males (Ma, Chu, Jackson, \& Tsou, In press). For example, at social events in Chinese homes, male guests are routinely offered cigarettes; and among certain male groups, having a cigarette after a meal is customary (Chen, Unger, \& Johnson, 1999). These social norms do not apply to women. Smoking among women is considered unbefitting female character, is unattractive to males, and is a sign of loose morals across Chinese, Vietnamese and Korean cultures (Ma, Chu, Jackson, \& Tsou, In press; Jenkins, Dai, \& Ngoc, 1997). While the current study shows that certain social influences are associated with current smokers, it also shows that the highest smoking rates were in the 22-45 age group. This finding may indicate that peer and parental influences may be influential beyond adolescence into young adulthood and that smoking begins at a later age for Asian Americans. Previous studies focusing on age of initiation have shown that smoking initiation occurs at a later time for Asian Americans than for other ethnic/racial groups (Wiecha, 1996; Wiecha et al., 1998), however, the current study indicates that the perception of peer influence is not perceived to be as pervasive as among the youngest age group.

These findings suggest that any successful smoking prevention and intervention strategy must emphasize the substantial impact that parents have on younger male smoking behavior. This impact is doubly significant because of cultural mores that encourage the 
development of the habit at an early age and the association of the habit with bliss.

While previous studies gave more weight to the influence of peer smoking friends on youth smoking behaviors (Hu et al., 1995; Landrine et al., 1994; Headen et al., 1991) our study showed equal influence of a smoking father and peer friends on male smoking. Further, we observed that current smokers were more likely to have friends who are current smokers than nonsmokers and to perceive higher percentages of peer smokers than nonsmokers. These findings should also be incorporated into smoking prevention and intervention strategies for Asian Americans, the former to counter friends' social influence on male and female smoking behavior, and the latter to correct misperceptions about peer smoking behaviors.
The study had three major limitations. First, data were based on self-reports and therefore may be underestimates of smoking behavior. Second, the study used a cross-sectional design and therefore cause and effect relationships could not be determined. For example, it would be difficult to determine if parental smoking behavior effected tobacco use in children. Third, due to certain cultural factors and sample characteristics, simple random selection was difficult to achieve because organizational membership lists were not accessible due to confidentiality issues. In addition, Asian respondents are typically reluctant to provide personal information to researchers. Regardless of these limitations, this study has shown unique social influence patterns on smoking behavior that should be considered in the development and implementation of smoking prevention and intervention programs among Asian Americans.

\section{References}

Baluja, K. F., Park, J., \& Myers, D. (2003). Inclusion of immigrant status in smoking prevalence statistics. American Journal of Public Health, 93, 642-646.

Bandura, A. (1986). Social foundations of thought and action: A social cognitive theory. Englewood Cliffs, NJ: Prentice Hall.

Bauman, K. L., Foshee, V. A., Linzer, M. A., \& Koch, G. C. (1990). Effects of parental smoking classification on the association between parental and adolescent smoking. Addictive Behaviors 15, 414-422.

Botvin, G. J., Epstein, J. A., Schinke, S. P., \& Diaz, T. (1994). Predictors of cigarette smoking among inner-city minority youth. Journal of Developmental and Behavioral Pediatrics, 15, 67-73.

Castro, F.G., Maddahian, E., Newcomb, M. D., \& Bentler, P. M. (1987). A multivariate model of the determinants of cigarette smoking among adolescents. Journal of Health and Social Behavior, 28, 273-289.

Centers for Disease Control and Prevention. (1992). Cigarette smoking among Southeast Asian immigrants - Washington State, 1989. Morbidity and Mortality Weekly Report, 41, 362-367.

Centers for Disease Control and Prevention. (1999). Cigarette smoking among adults - United States 1999. Morbidity and Mortality Weekly Report, 50, 869-873.

Chen, X, Unger, J. B, \& Johnson, C. A. (1999). Is acculturation a risk factor for early smoking initiation among Chinese American minors? A comparative perspective. Tobacco Control, 8, 402-410.

Dusenbury, L., Kerner, J. F., Baker, E., Botvin, G., James-Ortiz, S., \& Zanber, A. (1992). Predictors of smoking prevalence among New York Latino youth. American Journal of Public Health, 82, 5558.

Farrell, A. D. \& Danish, S. J. (1993). Peer drug association and emotional restraint: Causes or consequences of adolescents' drug use? Journal of Consuling \& Clinical Psychology, 61, 327 334.

Friedman, L.S., Lichtenstein, E., \& Biglan, A. (1985). Smoking onset among teens: an empirical analysis of initial situations. Addictive Behaviors, 10, 1-13.

Headen, S. W., Bauman, K. E., Deane, G. D., \& Koch, G. G. (1991). Are the correlates of cigarette smoking initiation different for Black and White adolescents? American Journal of Public Health, 81, 854-858. 
Hu, F. B., Flay, B. R., Hedeker, D., Siddiqui, O., \& Day, L. E. (1995). The influences of friends' and parental smoking on adolescent smoking behavior: The effects of time and prior smoking. Journal of Applied Social Psychology, 25, 2018-2047.

Jenkins, C. N., Dai, P. X., \& Ngoc, D. H. (1997). Tobacco use in Vietnam: Prevalence, predictors, and the role of the transnational tobacco corporation. Journal of the American Medical Association, 277, 1726-1731.

Landrine, H., Richardson, J. L., Klonoff, E. A., \& Flay, B. (1994). Cultural diversity in the predictors of adolescent cigarette smoking: The relative influence of peers. Journal of Behavioral Medicine, 17, 331-346.

Ma, G. X., Chu, K., Jackson, F., \& Tsou, W. (In press). Tobacco Control Efforts in Asian American Communities. Asian American and Pacific Islander Journal of Healths.

Ma, G. X., Shive, S., Tan, Y., \& Toubbeh, J. (2002). Prevalence and Predictors of smoking behaviors among Asian Americans. American Journal of Public Health, 92, 1013-1020.

Moor, C. D., Elder, J. P., Young, R. L., Wildey, M. B., \& Molgaard, C. A. (1989). Generic tobacco use among four ethnic groups in a school age population. Journal of Drug Education, 19, 257-270.

Moreno, C., Laniado-Laborin, R., \& Sallis, J. F. (1994). Parental influences to smoke in Latino youth. Preventive Medicine, 23, 48-53.

Morris, G. S., Vo, A. N., Bassin, S., Savaglio, D., \& Wong, N. D. (1993). Prevalence and sociobehavioral correlates of tobacco use among Hispanic children: The tobacco Resistance Activity Program. Journal of School Health, 63, 391-396.

Newcomb, M. D., \& Bentler, P. M. (1986). Substance use and ethnicity: Differential impact of peer and adult models. Journal of Psychology, 120, 83-95.

Newman, I. M., \& Ward, J. M. The influence of parental attitude and behavior on early adolescent cigarette smoking. Journal of School Health, 59, 150-152.

Nolte, A.E., Smith, B.J., \& O' Rourke T. The relative importance of parental attitudes and behavior upon youth smoking behavior. Journal of School Health, 53, 264-271.

Smith, K. W., McGraw, S. A., \& Carrillo, E. J. (1991). Factors affecting cigarette smoking and intention to smoke among Puerto Rican-American high school students. Hispanic Journal of Behavioral Science, $13,401-411$.

Sussman, S., Dent, C. W., Flay, B. R., Hansen, W. B., \& Johnson, C. A. (1987). Psychosocial predictors of cigarette smoking onset by White, Black, Hispanic, and Asian adolescents in Southern California. Morbidity Mortality Weekly Report, 36(Suppl.), 11S-16S.

U.S. Bureau of Census. (1990). 1990 Census of Population. (112th ed). Washington, DC: Government Printing Office.

U.S. Bureau of the Census. (2000). Current Population Survey, March 2000. Washington, DC: Government Printing Office.

U.S. Department of Health and Human Services. (2002). Application for a public health service grant PHS 398. 2002. Retrieved September 25, 2002, from http://grants1.nih.gov/grants/funding/phs398/phs398

Unger, J. B. \& Chen, X. (1999). The role of social networks and media receptivity in predicting age of smoking initiation: A proportional hazards model of risk and protective factors. Addictive Behaviors, 24, 371-381.

Vega, W. A., Zimmerman, R. S., Warheit, G. J., Apospori, E., \& Gil, A. G. (1993). Risk factors for early adolescent drug use in four ethnic and racial groups. American Journal of Public Health, 83, 185189.

Wiecha, J. M. (1996). Differences in pattern of tobacco use in Vietnamese, African-American, Hispanic, and Caucasian adolescents in Worcester, Massachusetts. American Journal of Preventive Medicine, 12, 29-37.

Wiecha, J. M., Lee, V., \& Hodgkins, J. (1998). Patterns of smoking, risk factor for smoking, and smoking cessation among Vietnamese men in Massachusetts (United States). Tobacco Control, 7, 27-34. 


\section{Acknowledgments}

We are grateful to members of Asian Community Cancer Coalition for their contributions to the study, to Rosemary Feeley in assisting with the data analysis and to Frank Jackson and Dr. Ken Chu for their support. This study was funded by the National Cancer Institute. The contents do not necessarily represent the views of the funding agency.

Author Information

Grace X. Ma, Ph.D., CHES

Associate Professor of Public Health

Department of Public Health

Principal Investigator \& Director

Center for ATECAR

College of Allied Health Professions

Temple University

304A Vivacqua Hall, P.O. Box 2843

Philadelphia, PA, USA 19122-0843

Email: grace.ma@temple.edu

Steven E. Shive, Ph.D., M.P.H.*

Research Associate of ATECAR, Temple University \&

Assistant Professor

Department of Health

East Stroudsburg University

200 Prospect St.

East Stroudsburg, PA 18301-2999

Jamil Toubbeh, Ph.D., Senior Researcher

Center for ATECAR

Adjunct Professor

Department of Public Health

Temple University

1415 N Broad St., Suite 116

Philadelphia, PA, USA 19122

Yin Tan, M.D., M.P.H.

Research Associate/Research Project Manager

Center for ATECAR

College of Allied Health Professions

Temple University

1415 N Broad St., Suite 116

Philadelphia, PA, USA 19122

Shanyang Zhao, Ph.D.

Associate Professor of Sociology Department

Biostatistician of Center for ATECAR

Temple University

Philadelphia, PA, USA 19122

* Corresponding author 